\section{Central Venous Catheter-Related Bloodstream Infections in Obese Hematologic Patients}

To the Editor-Central venous catheter (CVC)-related bloodstream infections (CRBSI) are associated with high morbidity, especially in neutropenic patients. ${ }^{1}$ In general, obesity is one of the risk factors associated with CRBSI. However, this finding is inconsistent in the literature and no data are available on patients with hematologic malignancies so far. CVC insertion is often technically challenging in obese patients owing to obscured landmarks of the neck. ${ }^{2,3}$ Furthermore, with increased sweating, ${ }^{4}$ bandages at the CVC insertion site are frequently problematic and lead to higher risk of CRBSI. ${ }^{5}$ Therefore, we hypothesized that obese hematologic patients treated with chemotherapy are at higher risk of having CRBSI than non-obese hematologic patients.

In the monocentric, prospective SECRECY registry (Study to Evaluate Central Venous Catheter-Related Infections in Hematology and Oncology; German Clinical Trial Register number, DRKS00006551) we evaluated CRBSI in all consecutive patients in our department from March 20, 2013, through March 13, 2015. The registry was approved by the local ethics committee (approval no. 84/14). Owing to anonymization of patients' data, written informed consent was not required within the registry. However, written informed consent is available for the procedure of CVC insertion during routine clinical use. All patients were at least 18 years of age. CVCs were mainly used for chemotherapy or best supportive care. All CVCs were inserted under sterile conditions and ultrasound guidance by experienced physicians. To define CRBSI we used the 2012 criteria of the Infectious Diseases Working Party of the German Society of Hematology and Medical Oncology. ${ }^{1}$ Obesity was defined as body mass index (BMI; calculated as weight in kilograms divided by height in meters squared) of 30 or greater according to the commonly known World Health Organization criteria.

Altogether we analyzed 335 triple-lumen, short-time CVCs (including 11 coated CVCs) that were in use at least 1 day. The CVCs accounted for a total of 5,094 CVC days (mean [range], 15.2 [1-60] days). The mean (range) age of the 176 patients was 58.1 (25-81) years; $106(60.2 \%)$ were men. Mostly, patients had acute leukemia (178 [53.1\%]), multiple myeloma (83 [24.8\%]), or malignant lymphoma (41 [12.2\%]). Patients received a mean (range) of 1.9 (1-6) CVC insertions within the observation period. Most CVCs (314 [93.7\%]) were inserted into the internal jugular vein. CRBSI were detected in 77 cases (12 [15.6\%] definite, 21 [27.3\%] probable, 44 [57.1\%] possible), with an incidence of 15.1/1,000 CVC-days and an incidence rate of $23.0 \%$. The most prevalent pathogen was Staphylococcus epidermidis (43 [71.7\%]). At baseline-that is, at time of the first CVC insertion of the patients, the mean
TABle 1. Data on 176 Patients, Use of 335 Central Venous Catheters (CVCs), and Occurrence of Catheter-Related Bloodstream Infection (CRBSI)

\begin{tabular}{|c|c|c|}
\hline Variable & Value & \\
\hline \multicolumn{3}{|l|}{ Patients, $n=176$} \\
\hline Age, mean (range), y & $58.1(25-81)$ & \\
\hline Male sex, no. $(\%)$ & $106(60.2)$ & \\
\hline Body mass index, mean (range) & $28.0(15-46)$ & \\
\hline \multicolumn{3}{|l|}{ CVCs, $n=335$} \\
\hline CVC-days, total & 5,094 & \\
\hline CVC-days, mean (range) & $15.2(1-60)$ & \\
\hline \multicolumn{3}{|l|}{ Inserted vein, no. (\%) of CVCs } \\
\hline Internal jugular vein & $314(93.7 \%)$ & \\
\hline Right & $194 / 314(61.8 \%)$ & \\
\hline Subclavian vein & $14(4.2 \%)$ & \\
\hline Femoral vein & $7(2.1 \%)$ & \\
\hline \multicolumn{3}{|l|}{$\begin{array}{l}\text { Underlying disease in patient, no. (\%) } \\
\text { of CVCs }\end{array}$} \\
\hline Acute leukemia & $178(53.1 \%)$ & \\
\hline Multiple myeloma & $83(24.8 \%)$ & \\
\hline Malignant lymphoma & $41(12.2 \%)$ & \\
\hline Others & $33(9.9 \%)$ & \\
\hline \multicolumn{3}{|l|}{ CRBSI, $n=77$} \\
\hline Definite & $12(15.6 \%)$ & \\
\hline Probable & $21(27.3 \%)$ & \\
\hline Possible & $44(57.1 \%)$ & \\
\hline CRBSI incidence per 1,000 CVC-days & 15.1 & \\
\hline Definite & 2.4 & \\
\hline Probable & 4.1 & \\
\hline Possible & 8.6 & \\
\hline CRBSI incidence rate & $23.0 \%$ & \\
\hline Definite & $3.6 \%$ & \\
\hline Probable & $6.3 \%$ & \\
\hline Possible & $13.1 \%$ & \\
\hline \multicolumn{3}{|l|}{ Underlying pathogens, no. (\%) } \\
\hline Staphylococcus epidermidis & $43 / 60(71.7 \%)$ & \\
\hline Staphylococcus haemolyticus & $5 / 60(8.3 \%)$ & \\
\hline Other & $12 / 60(20.0 \%)$ & \\
\hline \multicolumn{3}{|l|}{ Obesity data } \\
\hline BMI, mean (range) & $27.3(15-46)$ & \\
\hline $\begin{array}{l}\text { No. of CVCs in obese patients } \\
(\% \text { of all CVCs) }\end{array}$ & $95(28.4 \%)$ & \\
\hline $\begin{array}{l}\text { Risk for complicated CVC insertion, } \\
\text { OR }(95 \% \text { CI })\end{array}$ & $0.99(0.53-1.85)$ & $P>.99^{\mathrm{a}}$ \\
\hline Obese vs non-obese & $\begin{array}{c}17 / 93(18.3 \%) \text { vs } 43 / 234 \\
(18.4 \%)\end{array}$ & \\
\hline Risk for CRBSI, OR (95\% CI) & $0.93(0.53-1.65)$ & $P=.93^{\mathrm{a}}$ \\
\hline Obese vs non-obese & $\begin{array}{c}21 / 95(22.1 \%) \text { vs } 56 / 240 \\
(23.3 \%)\end{array}$ & \\
\hline \multicolumn{3}{|l|}{$\mathrm{CVC}$ in use } \\
\hline Obese vs non-obese & 13.5 days vs 15.9 days & $P=.03^{\mathrm{b}}$ \\
\hline \multicolumn{3}{|l|}{ mIPS at CVC insertion } \\
\hline Obese vs non-obese & 7.6 vs 5.8 & $P=.02^{\mathrm{b}}$ \\
\hline \multicolumn{3}{|l|}{ mIPS at CVC removal } \\
\hline Obese vs non-obese & 9.7 vs 8.2 & $P=.06^{\mathrm{b}}$ \\
\hline \multicolumn{3}{|l|}{ Age, y } \\
\hline Obese vs non-obese & 57.5 vs 59.5 & $P=.16^{\mathrm{b}}$ \\
\hline $\begin{array}{l}\text { Men and risk for CRBSI, OR } \\
(95 \% \mathrm{CI})\end{array}$ & $0.68(0.32-1.45)$ & $P=.42^{\mathrm{a}}$ \\
\hline Obese vs non-obese & $\begin{array}{c}11 / 52(21.2 \%) \text { vs } 42 / 149 \\
(28.2 \%)\end{array}$ & \\
\hline $\begin{array}{l}\text { Women and risk for CRBSI, OR } \\
(95 \% \mathrm{CI})\end{array}$ & $1.58(0.64-3.92)$ & $P=.45^{\mathrm{a}}$ \\
\hline Obese vs non-obese & $10 / 43(23.3 \%)$ vs $14 / 91(15.4 \%)$ & \\
\hline
\end{tabular}

NOTE. Body mass index (BMI) is calculated as weight in kilograms divided by height in meters squared. Obesity is defined as $B M I \geq 30$. mIPS, modified Infection Probability Score; OR, odds ratio.

${ }^{a}$ Fisher exact test.

${ }^{\mathrm{b}}$ Student $t$ test. 
(range) BMI was 28.0 (15-46). Taking all 335 CVCs together, the BMI of the patients was a mean of 27.3 , whereas in 95 CVCs (28.4\%), the BMI of the patients was at least 30 (for the subgroup of the obese patients the mean BMI was 33.8).

Complications of CVC insertion (bleeding, hematoma, $>2$ punctures, or malpositioning of the guidewire) were reported in $18.3 \%$ of obese patients and in $18.4 \%$ of non-obese patients. This indicates no increased risk for complications during CVC insertion among obese patients (odds ratio [OR], 0.99].

Comparing the CRBSI rate in obese and in non-obese patients we found no differences in CRBSI frequency $(22.1 \%$ vs $23.3 \%$; OR, 0.93).

Duration of CVC use appeared to be significantly shorter in obese compared with non-obese patients (13.5 vs 15.9 days). However, using the modified Infection Probability Score, ${ }^{6}$ which is more stringent in defining neutropenia than the original IPS, ${ }^{7}$ we found a higher modified Infection Probability Score at the time of CVC insertion in obese than in non-obese patients (7.6 vs 5.8). Interestingly, sex is not a risk factor for CRBSI in obese patients (men vs women, OR, 0.86 [95\% CI, 0.32-2.35]; $P=.97$ ). CRBSI risk was increased neither for obese men $(\mathrm{OR}, 0.68)$ nor for obese women $(\mathrm{OR}, 1.58)$ (data are summarized in Table 1).

In our experience, CVC insertion with support of ultrasonography is a safe procedure in obese hematologic patients. Surprisingly, obesity could not be defined as a risk factor for CRBSI in our dataset. Using the modified Infection Probability Score ${ }^{6}$ as a tool to describe the grade of illness of patients (with all critical parameters such as body temperature, heart rate, respiratory rate, absolute neutrophil count, and C-reactive protein as well as the Sequential Organ Failure Assessment score ${ }^{8}$ being included), we found that obese patients had increased values and were therefore more challenged by the disease at the time of CVC insertion; however, the risk for CRBSI per se was not increased. One potential pitfall that could mask the CRBSI risk in obese patients is the duration of CVC use, which was significantly shorter (2-3 days shorter) in obese vs non-obese patients in the cohort investigated. CRBSI are known to be associated with the duration of CVC use. ${ }^{6,9}$

Another piece of data supporting our findings is the inverse association between obesity and risk of febrile neutropenia that has been reported recently. ${ }^{10}$ Potential mechanisms include altered pharmacokinetics and/or reduced relative efficacy of chemotherapy due to obesity. ${ }^{10}$

\section{ACKNOWLEDGMENTS}

Financial support. None reported.

Potential conflicts of interest. All authors report no conflicts of interest relevant to this article.
Affiliations: 1. Department of Hematology and Oncology, Medical Center, Otto-von-Guericke University Magdeburg, Magdeburg, Germany; 2. Department of Medical Microbiology, Infection Control and Prevention, Medical Center, Otto-von-Guericke University Magdeburg, Magdeburg, Germany.

Address correspondence to Enrico Schalk, MD, Department of Hematology and Oncology, Medical Center, Otto-von-Guericke University Magdeburg, Leipziger Str. 44, D-39120 Magdeburg, Germany (enrico.schalk@med.ovgu.de). Infect Control Hosp Epidemiol 2015;36(8):995-996

(C) 2015 by The Society for Healthcare Epidemiology of America. All rights reserved. 0899-823X/2015/3608-0023. DOI: 10.1017/ice.2015.107

\section{REFERENCES}

1. Hentrich M, Schalk E, Schmidt-Hieber M, et al. Central venous catheter-related infections in hematology and oncology: 2012 updated guidelines on diagnosis, management and prevention by the Infectious Diseases Working Party of the German Society of Hematology and Medical Oncology. Ann Oncol 2014;25:936-947.

2. Graham AS, Ozment C, Tegtmeyer K, Lai S, Braner DA. Central venous catheterization. $N$ Engl J Med 2007;356:e21.

3. McGee DC, Gould MK. Preventing complications of central venous catheterization. $N$ Engl J Med 2003;348:1123-1133.

4. Lawrence VJ, Kopelman PG. Medical consequences of obesity. Clin Dermatol 2004;22:296-302.

5. Trick WE, Miranda J, Evans AT, Charles-Damte M, Reilly BM, Clarke P. Prospective cohort study of central venous catheters among internal medicine ward patients. Am J Infect Control 2006;34:636-641.

6. Schalk E, Hanus L, Färber J, Fischer T, Heidel FH. Prediction of central venous catheter-related bloodstream infections (CRBSIs) in patients with haematologic malignancies using a modified Infection Probability Score (mIPS). Ann Hematol 2015 (in press); doi: 10.1007/s00277-015-2387-y.

7. Peres Bota D, Mélot C, Lopes Ferreira F, Vincent JL. Infection Probability Score (IPS): a method to help assess the probability of infection in critically ill patients. Crit Care Med 2003;31:2579-2584.

8. Vincent JL, Moreno R, Takala J, et al. The SOFA (Sepsis-related Organ Failure Assessment) score to describe organ dysfunction/ failure: on behalf of the Working Group on Sepsis-Related Problems of the European Society of Intensive Care Medicine. Intensive Care Med 1996;22:707-710.

9. Pepin CS, Thom KA, Sorkin JD, et al. Risk factors for central lineassociated bloodstream infections: a focus on comorbid conditions. Infect Control Hosp Epidemiol 2015;36:479-481.

10. Chao C, Page JH, Yang SJ, Rodriguez R, Huynh J, Chia VM. History of chronic comorbidity and risk of chemotherapyinduced febrile neutropenia in cancer patients not receiving G-CSF prophylaxis. Ann Oncol 2014;25:1821-1829.

\section{Patients with Psychiatric Disorders Can Also Have CLABSIs: A Response to "CLABSI or Munchausen's or Both"}

To the Editor-We read with interest the recent article "CLABSI or Munchausen's or Both" ${ }^{1}$ because, among other aspects, it addressed the interactions between patient
Enrico Schalk, $\mathrm{MD} ;^{1}$
Jacqueline Färber, $\mathrm{MD} ;^{2}$
Thomas Fischer, $\mathrm{MD}^{1}$
Florian H. Heidel, $\mathrm{MD}^{1}$ 